\title{
Resonance-enhanced detection of metals in aerosols using single-particle mass spectrometry
}

\author{
Johannes Passig 1,2,3, Julian Schade ${ }^{2,3}$, Ellen Iva Rosewig 2,3 , Robert Irsig ${ }^{3,4}$, Thomas Kröger-Badge ${ }^{2,3}$, \\ Hendryk Czech ${ }^{1,2,3}$, Martin Sklorz ${ }^{1}$, Thorsten Streibel ${ }^{1,2}$, Lei $\mathbf{L i}^{5,6}$, Xue Li ${ }^{5,6}$, Zhen Zhou ${ }^{5,6}$, Henrik Fallgren ${ }^{7}$, \\ Jana Moldanova ${ }^{7}$, and Ralf Zimmermann ${ }^{1,2,3}$ \\ ${ }^{1}$ Joint Mass Spectrometry Centre, Cooperation Group "Comprehensive Molecular Analytics" (CMA), \\ Helmholtz Zentrum München, 85764 Neuherberg, Germany \\ ${ }^{2}$ Joint Mass Spectrometry Centre, Chair of Analytical Chemistry, University Rostock, 18059 Rostock, Germany \\ ${ }^{3}$ Department Life, Light \& Matter, University of Rostock, 18051 Rostock, Germany \\ ${ }^{4}$ Photonion GmbH, 19061 Schwerin, Germany \\ ${ }^{5}$ Institute of Mass Spectrometry and Atmospheric Environment, Jinan University, Guangzhou 510632, China \\ ${ }^{6}$ Guangzhou Hexin Instrument Co., Ltd, Guangzhou 510530, China \\ ${ }^{7}$ IVL Swedish Environmental Research Institute, 41133 Gothenburg, Sweden
}

Correspondence: Johannes Passig (johannes.passig@uni-rostock.de)

Received: 11 January 2020 - Discussion started: 20 January 2020

Revised: 3 May 2020 - Accepted: 15 May 2020 - Published: 18 June 2020

\begin{abstract}
We describe resonance effects in laser desorptionionization (LDI) of particles that substantially increase the sensitivity and selectivity to metals in single-particle mass spectrometry (SPMS). Within the proposed scenario, resonant light absorption by ablated metal atoms increases their ionization rate within a single laser pulse. By choosing the appropriate laser wavelength, the key micronutrients $\mathrm{Fe}, \mathrm{Zn}$ and $\mathrm{Mn}$ can be detected on individual aerosol particles with considerably improved efficiency. These ionization enhancements for metals apply to natural dust and anthropogenic aerosols, both important sources of bioavailable metals to marine environments. Transferring the results into applications, we show that the spectrum of our KrF-excimer laser is in resonance with a major absorption line of iron atoms. To estimate the impact of resonant LDI on the metal detection efficiency in SPMS applications, we performed a field experiment on ambient air with two alternately firing excimer lasers of different wavelengths. Herein, resonant LDI with the $\mathrm{KrF}$-excimer laser $(248.3 \mathrm{~nm})$ revealed iron signatures for many more particles of the same aerosol ensemble compared to the more common ArF-excimer laser line of $193.3 \mathrm{~nm}$ (nonresonant LDI of iron). Many of the particles that showed iron contents upon resonant LDI were mixtures of sea salt and organic carbon. For nonresonant ionization,
\end{abstract}

iron was exclusively detected in particles with a soot contribution. This suggests that resonant LDI allows a more universal and secure metal detection in SPMS. Moreover, our field study indicates relevant atmospheric iron transport by mixed organic particles, a pathway that might be underestimated in SPMS measurements based on nonresonant LDI. Our findings show a way to improve the detection and source attribution capabilities of SPMS for particle-bound metals, a health-relevant aerosol component and an important source of micronutrients to the surface oceans affecting marine primary productivity.

\section{Introduction}

Natural and anthropogenic aerosols play a pivotal role in global climate and biogeochemical cycles, yet limited available ambient observations result in large uncertainties. While sulfate and carbonaceous aerosols are intensively investigated for their climate effects (Wang et al., 2016; Seinfeld and Pandis, 2016; Kanakidou et al., 2005; Bond et al., 2013; Sofiev et al., 2018), the particle-bound metals have far-reaching impacts on ecosystems and human health. The redox cycling activity of inhaled transition metals such as 
iron $(\mathrm{Fe})$ induces oxidative stress and is involved in severe health effects from air pollution (Ye et al., 2018; Oakes et al., 2012; Fang et al., 2017). Furthermore, atmospheric particles are important sources of marine micronutrients (Mahowald et al., 2018; Jickells et al., 2005). The highly soluble and thus more bioavailable $\mathrm{Fe}$ from anthropogenic aerosols that adds to the larger flux of rather insoluble mineral dust is assumed to affect primary production and carbon export in a significant part of the world's oceans (Ito and Shi, 2016; Li et al., 2017; Ito, 2015). Beyond Fe, further biologically important trace metals exert health effects (Gaur and Agnihotri, 2019) or can modulate primary production (Mahowald et al., 2018). For example, as enzyme cofactors they can determine which enzymes cells can express, affecting the composition of microbial communities (Boyd et al., 2017). Productivitylimiting deficiencies of, e.g., manganese $(\mathrm{Mn})$ and zinc $(\mathrm{Zn})$ have been reported for marine regions (Mahowald et al., 2018). Zinc is also associated with toxicological responses to wood combustion aerosols (Uski et al., 2015; Kanashova et al., 2018). However, the magnitude and variability of anthropogenic sources of bioavailable metals in the sea are poorly characterized. Recently, anthropogenic fluxes and sources of $\mathrm{Fe}$ were estimated using isotope fingerprinting (Conway et al., 2019). Such studies require measurable differences between natural and anthropogenic isotope distributions of the respective metals. Alternative methods, preferably providing detailed source information, indicating the metal's bioavailability and acquiring episodic deposition events are required to refine the global distribution models with observational data.

Several mass-spectrometry-based analytical techniques for aerosol characterization have been developed, with single-particle mass spectrometry (SPMS) being a real-time method obtaining the size and a chemical profile from individual particles (Pratt and Prather, 2012; Laskin et al., 2018). In SPMS, the particles are introduced into a vacuum, individually sized and exposed to intense UV laser pulses that form a partly ionized plume (laser desorption-ionization, LDI) (Hinz and Spengler, 2007; Murphy, 2007). Ions are extracted and analyzed with respect to their mass-to-charge ratio $(m / z)$. Typically observed ions are, e.g., organic fragments, salts, ammonia, nitrate, sulfate, alkali metals, mineral components such as silicate, and carbon clusters from elemental or organic carbon (EC or OC). Along with the singleparticle aspect, SPMS stands out for its metal detection capabilities that yield unique source information data (Dall'Osto et al., 2016a, b; Pratt and Prather, 2012; Arndt et al., 2017). For example, vanadium can indicate ship emissions (Healy et al., 2009; Ault et al., 2010) and signal patterns of, e.g., aluminum, silicon and calcium point on soil dust particles (Sullivan et al., 2007). However, compound-specific ionization efficiencies differ significantly. For example, the particle's humidity and its main composition can have a strong effect on the detection of particle compounds (Neubauer et al., 1998), known as matrix effects. These effects are associated with several poorly determined interactions at the particle surface and in the desorbed plume affect ion formation (Reilly et al., 2000; Reinard and Johnston, 2008; Hinz and Spengler, 2007; Murphy, 2007; Wade et al., 2008; Hatch et al., 2014; Schoolcraft et al., 2000), reduce detection efficiencies, and complicate quantification approaches (Healy et al., 2013; Gemayel et al., 2017; Gross et al., 2000; Fergenson et al., 2001; Qin et al., 2006; Zhou et al., 2016; Shen et al., 2019). These difficulties can be mitigated if the desorption and ionization are separated in a two-step process and ions are formed in the gaseous plume as demonstrated for aromatic hydrocarbons (Morrical et al., 1998; Bente et al., 2008; Woods et al., 2001). In such a two-step approach, thermal or laser desorption (LD) is often followed by resonance-enhanced multiphoton ionization (REMPI), a gas-phase ionization technique that is highly sensitive and selective for aromatic molecules (Gunzer et al., 2019). The LD-REMPI approach yields detailed mass spectra of the health-relevant polycyclic aromatic hydrocarbons (PAHs) - ubiquitous trace compounds of combustion particles (Bente et al., 2009; Li et al., 2019; Passig et al., 2017; Schade et al., 2019). Resonant laser ablation of metals, where the leading edge of the laser pulse ablates atoms from a solid sample that are then ionized by the same pulse, have been studied some time ago for laser microprobe mass analysis (LAMMA) from surfaces (Verdun et al., 1987; McLean et al., 1990). However, to the best of our knowledge, such effects have so far not been recognized and applied in aerosol and single-particle mass spectrometry. In the current study, we report on such wavelength-dependent enhancements in LDI ion yields of transition metals from aerosol particles. Using an optical parametric oscillator (OPO), we demonstrate that besides Fe, the sparsely detected and biologically relevant trace metals $\mathrm{Zn}$ and $\mathrm{Mn}$ can also be observed in anthropogenic particles with much higher sensitivity. We show that the resonant absorption of iron coincides with the spectrum of the field-deployable KrF-excimer laser and with the REMPI absorption spectra of most aromatic molecules. Thus, the enhanced detection sensitivity for metals can be combined with detailed spectra of aromatic substances via REMPI. Finally, we demonstrate the application potential of the resonance effects in a field study comparing the $\mathrm{KrF}$-excimer laser with a commonly used ArF-excimer laser for their $\mathrm{Fe}$ detection capabilities in ambient aerosols. We found that resonant LDI also reveals $\mathrm{Fe}$ signatures in particle types that produced no Fe signals upon nonresonant LDI, suggesting that the relevance of organic aerosols and salts as a source for Fe might have been underestimated in earlier SPMS studies.

\section{Methods}

\subsection{Single-particle mass spectrometer and optical setup}

The basic SPMS instrument (Hexin Instruments Ltd., Guangzhou, China, and Photonion GmbH, Schwerin, Ger- 
many) is described in other publications ( $\mathrm{Li}$ et al., 2011). Briefly, its instrumental layout is conceptually close to the aerosol time-of-flight mass spectrometer (ATOF-MS) (Su et al., 2004), with an aerodynamic lens inlet and an optical sizing unit that is comprised of a pair of $75 \mathrm{~mW}$ continuouswave lasers at a wavelength of $532 \mathrm{~nm}$, ellipsoidal mirrors and photomultipliers. The dual-polarity mass spectrometer is designed in Z-TOF geometry, as introduced by Pratt et al. (2009). For further details, e.g., the inlet particle transmission and detection efficiency, we refer to the literature (Li et al., 2011; Zhou et al., 2016). After the laboratory experiments, we implemented delayed ion extraction ( $\Delta t=0.4 \mu \mathrm{s}$ ) using high-voltage switches (HTS31-03-GSM, Behlke GmbH, Germany) to improve the peak quality in the ambient air experiments (Vera et al., 2005; Li et al., 2018). Major modifications to the commercial device are made to the ionization laser and the optical setup. We equipped the instrument with both a tuneable laser system (optical parametric oscillator, OPO) and excimer lasers $(\lambda=248 \mathrm{~nm}$ and $\lambda=193 \mathrm{~nm}$ ) and replaced the Nd:YAG solid-state laser ( $\lambda=266 \mathrm{~nm}$, fourth harmonic frequency) that belongs to the instruments standard configuration. Apart from the wavelength, most beam parameters were comparable throughout the experiments; see Table 1 for details. The pulse energy was measured at the optical entrance and exit of the mass spectrometer and the position of the focal lens $(f=200 \mathrm{~mm})$ was adjusted to maintain a comparable spot area, with a respective intensity for all wavelength comparison experiments. The OPO wavelengths and the $\mathrm{KrF}$-excimer laser spectrum were measured with a LRL-005 spectrometer (MK Photonics Inc. USA).

\subsection{Data analysis}

In the laboratory experiments, only particles with both a positive and negative ion spectrum, each showing at least two peaks above the noise level, were considered. Raw timeof-flight data were converted to mass spectra considering peak area within nominal mass resolution by custom software on MATLAB platform (MathWorks Inc.). For particle classification in the ambient air study, we utilized the adaptive resonance theory neural network, ART-2a (Song et al., 1999) from the open-source toolkit FATES (Flexible Analysis Toolkit for the Exploration of SPMS data) (Sultana et al., 2017) with a learning rate 0.05 , a vigilance factor of 0.8 and 20 iterations.

\subsection{Model particles, sampling and setup for ambient air experiments}

Diesel exhaust particles from an old van (Volkswagen Transporter 1.7 D, 1988 model) were collected from the inner surface of the exhaust tube. These particles exhibit a rather uniform chemical composition, as demonstrated in previous experiments (Passig et al., 2017; Schade et al., 2019). Model particles for mineral dust were Arizona test dust $0-3 \mu \mathrm{m}$ diameter (Powder Technology Inc., USA), and complex anthropogenic aerosols with trace metals were mimicked using NIST urban dust 1649b (Gonzalez and Choquette, 2016). Using a turntable-based powder disperser (Model 3433, TSI Inc., USA), particles were introduced into a $1 \mathrm{Lmin}^{-1}$ carrier gas stream ( $\mathrm{N}_{2}$, purity: 5.0) from which $0.1 \mathrm{~L} \mathrm{~min}^{-1}$ were guided in an isokinetic flow into the instrument. For the experiments on ambient air, the SPMS instrument was set up at a meteorological station in a rural environment on the western coast of Sweden, about $30 \mathrm{~km}$ south of Gothenburg (coordinates $\left.57^{\circ} 23^{\prime} 37.8^{\prime \prime} \mathrm{N}, 11^{\circ} 54^{\prime} 51.4^{\prime \prime} \mathrm{E}\right)$. Ambient air was sampled at a height of $7 \mathrm{~m}$ above ground $(15 \mathrm{~m}$ above sea level). Aerosols from a $300 \mathrm{~L} \mathrm{~min}^{-1}$ intake airflow were concentrated into the $1 \mathrm{~L} \mathrm{~min}^{-1}$ carrier gas stream first using a virtual impactor device (Model 4240, MSP corp., USA). After passing a dryer (Model MD-700-12S-1, Perma Pure LLC, USA), they were further concentrated to $0.1 \mathrm{~L} \mathrm{~min}^{-1}$ in a second step directly at the SPMS aerodynamic lens inlet. The concentration is most effective for particles of around $1 \mu \mathrm{m}$ in size, while it drops below $0.5 \mu \mathrm{m}$; see Fig. $\mathrm{S} 1$ in the Supplement for a comparison of particle numbers in ambient air with and without using the concentrator. The two KrF and $\mathrm{ArF}$ excimer lasers used in this experiment were alternately triggered to particles using a custom electronic circuit based on a complex programmable logic device (Intel Max V) with $8.5 \mathrm{~ns}$ pin-to-pin delay and programmed using the Very High Speed Integrated Circuit Hardware Description Language (VHDL). The excimer laser beams were focused from opposite sides onto the particle beam; see Table 1 and Sect. 3.3 for details.

\section{Results and discussion}

\subsection{Resonance enhancements of $\mathrm{Fe}$ signals}

We measured the Fe signals from diesel soot and Arizona desert dust particles as representative models of relevant anthropogenic and natural aerosols transporting $\mathrm{Fe}$ into the oceans. Figure $1 \mathrm{a}$ and $\mathrm{b}$ show the respective mass spectra of positive and negative ions from LDI with two different wavelengths using the OPO. The mass spectra were accumulated over every 400 particles, without normalization or further processing. The observed peak-broadening results mainly from accumulation over single-particle spectra with varying ion energy and starting positions. Typical signatures for (diesel) engine emissions (Toner et al., 2006) are recognizable, e.g., clusters of elemental carbon (EC, from soot) and organic hydrocarbon fragments (OC) (Silva and Prather, 2000). Also, alkali metals are frequently detected due to their low ionization energy. The desert dust particles (Fig. 1b) reveal typical mineral dust signals from metals and metal oxides (Sullivan et al., 2007; Dall'Osto et al., 2010). The slightly different laser wavelengths yield rather similar mass 
Table 1. Light sources and details of the optical setup.

\begin{tabular}{|c|c|c|c|}
\hline Laser source & $\begin{array}{l}\text { Opolette HE } 355 \text { LD UV, } \\
\text { Opotek LLC, USA }\end{array}$ & $\begin{array}{l}\text { PhotonEx, Photonion } \\
\text { GmbH, Germany }\end{array}$ & $\begin{array}{l}\text { ATLEX-I 300, ATL } \\
\text { GmbH, Germany }\end{array}$ \\
\hline Laser medium & $\begin{array}{l}\text { Optical Parametric Oscillator, } \\
\text { Nd:YAG pumped }\end{array}$ & KrF gas (excimer) & ArF gas (excimer) \\
\hline Wavelength (nm), photon energy (eV) & Tuneable 210-2400 & $248,4.99$ & $193,6.41$ \\
\hline Pulse duration (ns) & & $\approx 5$ & \\
\hline Beam size $(\mathrm{mm})$ & Ø3 nearly Gaussian & $\begin{array}{l}3 \times 6 \quad \text { Gaussian } \times \text { flat } \\
\text { top }\end{array}$ & $\begin{array}{l}3 \times 6 \text { Gaussian } \times \text { flat } \\
\text { top }\end{array}$ \\
\hline Interaction spot distance to focus (mm) & $\approx 8-11$ & 7 & 7 \\
\hline Rayleigh length (mm) & $\approx 1.2-1.5$ & 1.4 & 1.1 \\
\hline Interaction spot size $(\mu \mathrm{m})$ & $\varnothing 160$ & $105 \times 210$ & $105 \times 210$ \\
\hline Pulse energy (mJ) & 0.4 & & \\
\hline Pulse intensity at interaction spot $\left(\mathrm{GW} \mathrm{cm}^{-2}\right)$ & 0.8 & & \\
\hline
\end{tabular}

spectra. However, much stronger Fe signals can be observed for $248.3 \mathrm{~nm}$ for both particle types (see insets in Fig. 1a and b). This wavelength matches the $3 d^{6} 4 s^{2} \rightarrow 3 d^{6} 4 s 4 p$ transition of Fe atoms, a line that is also typically used for Fe determination in atomic absorption spectroscopy. As apparent from the histogram plots in Fig. 1c and d, the enhancement effect does not result from some especially Fe-rich particles. Instead, most particles show higher Fe signals at the resonance wavelength, and the fraction of particles without $\mathrm{Fe}$ signals drops considerably. However, the high Fe content of Arizona dust particles $(\approx 4 \%-7 \%)$ often leads to saturated signals on the single-particle level. Even stronger saturation effects producing highly corrupted Fe peaks were observed for hematite, which is consequently not shown here. Because interferences with $\mathrm{CaO}^{+}$and organic fragments such as $\mathrm{C}_{3} \mathrm{H}_{4} \mathrm{O}^{+}$can affect the signal differences at $m / z=56$, the histograms show the signal of the ${ }^{54} \mathrm{Fe}$ isotope. Contributions from organic fragments to $m / z=54$ are assumed to be rather small, as apparent from the signal strengths of principal fragments in the respective mass range at $m / z=51$, 53 and 55; see inset of Fig. 1a. However, such interferences might lead to a moderate underestimation of the resonance enhancement. A further resonance effect can be noticed for lithium at the reference wavelength of $242.2 \mathrm{~nm}$ because of the $1 s^{2} 2 s \rightarrow 1 s^{2} 7 p$ transition close to this wavelength. Experimental results on hemoglobin powder, representing a particle model with uniform organic composition, are shown in Fig. S4 and confirm the resonance enhancements for Fe.

To further investigate the enhancement effects, we measured the wavelength-dependent total ion yield of ${ }^{54} \mathrm{Fe}$ from every 1200 particles, exposed to OPO laser pulses of the same intensity. As shown in Fig. 2, the maximum Fe signal is achieved near the resonance, with a 3-4-fold enhancement for diesel soot and mineral dust particles and hemoglobin particles; see Fig. S4. The ion yield curves have a remarkable width and are much broader than the atomic lines or the OPO linewidth $\left(4-6 \mathrm{~cm}^{-1}\right)$. The absorption spectrum of $\mathrm{Fe}$ atoms (blue) represents data from the NIST atomic spectra library (Kramida et al., 2019). Such signal enhancements at specific wavelengths were not reported in previous SPMS studies, apart from the aforementioned REMPI techniques. Thomson et al. (1997) observed that the threshold intensity for ion formation decreased with increasing absorbance of the bulk material for different salts. Generally, more substances are ionized at higher photon energies and lower laser intensities are required, but these effects tend to saturate at higher laser intensities (Thomson et al., 1997; Murphy, 2007). Even in a study using two matrix-assisted LDI (MALDI) matrix materials absorbing at different wavelengths, Wade et al. (2008) found only minimal wavelength effects on ion yields but a stronger dependence on the intensity and particle size. However, these results are not conflicting with the Fe resonance we observed. Several studies indicate that above a minimum intensity, effects in the plume dominate the ionization yield rather than the absorbance of the particle itself (Carson et al., 1997; Wade et al., 2008; Reinard and Johnston, 2008). The resonance begins to take effect as soon as Fe atoms are formed and vaporized from the particle during the initial phase of the laser pulse.

While not recognized for SPMS so far, such resonance enhancements were previously reported and explained for laser ablation from solid surfaces. Using dye lasers, about 5-fold signal increases were observed at the atomic lines of several metals and semiconductors (Verdun et al., 1987). The widths of the resonances were also rather broad, i.e., 0.4 $0.7 \mathrm{~nm}$. For low laser intensity, grazing incidence and twostep excitation, the width dropped below $0.05 \mathrm{~nm}$ (McLean et al., 1990) approaching the values of the respective atoms in 

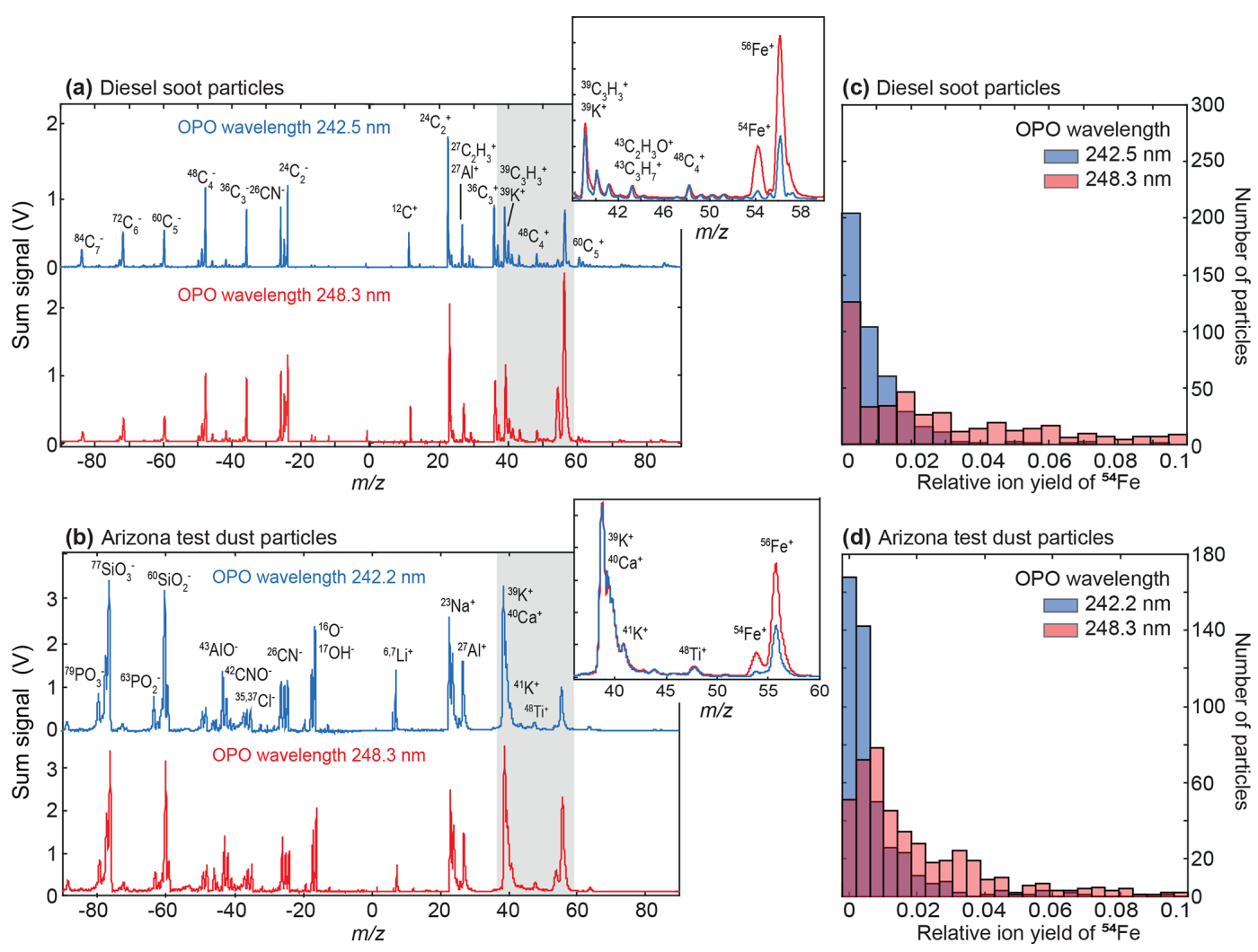

Figure 1. (a) Accumulated mass spectra (every $n=400$ ) of re-dispersed diesel soot particles ionized using the tuneable OPO laser. In the case of resonant ionization of $\mathrm{Fe}$ at $248.3 \mathrm{~nm}$ (red), the Fe signal is substantially enhanced compared to the nonresonant ionization at $242.5 \mathrm{~nm}$ (blue); see the inset for an enlarged view of the grey area. Most other signals are similar. (b) A comparable Fe enhancement can be observed for mineral dust particles. The histogram panels (c) and (d) of the single-particle relative ion signal $\left({ }^{54} \mathrm{Fe}^{+}\right.$signal normalized to the particle's total ion yield) illustrate that the ionization enhancement accounts for the majority of analyzed particles. Corresponding normalized mass spectra are shown in Fig. S2, and the particle size distributions are depicted in Fig. S3.

gas-phase ionization (resonant ionization MS, RIMS; Young et al., 1989). The explanation for the broad signals in resonant ablation from surfaces and particles is rather simple: broadening and transition wavelength shifts can be expected if the excitation happens when atoms are still bound in the matrix close to the surface (Verdun et al., 1987; McLean et al., 1990). Additionally, the plasma pressure could contribute to these effects. With increasing time and distance from the dense target, the surface bonds vanish and the conditions become similar to RIMS. Minor contributions to the measured width could result from Stark broadening (typically at higher laser power; Hübert and Ankerhold, 2011) and interferences with the adjacent absorption lines.

\subsection{Resonance enhancements of trace metals}

The resonant ionization of particle-bound Fe raises the question whether the SPMS-based detection of other biologically relevant metals may also benefit from the enhancement. We used NIST reference material urban dust $1649 \mathrm{~b}$ (National Standard Institute of Technology, USA) as a wellcharacterized anthropogenic particle model containing sev- eral transition metals at low concentrations. Figure 3 shows accumulated cation mass spectra from resonant and nonresonant ionization with respect to strong atomic lines of $\mathrm{Fe}, \mathrm{Mn}$ and $\mathrm{Zn}$. The mass fraction of $\mathrm{Fe}$ is rather high $(\approx 3 \%)$ and the signal enhancement at $248.3 \mathrm{~nm}$ (see Fig. 3a) corresponds to the results from diesel soot and Arizona dust. Manganese contributes a mass fraction of only $0.024 \%$ to the dust. In general, for particles with organic content, the Mn signature at $m / z=55$ can hardly be distinguished from molecular fragments of the same mass. However, when the OPO wavelength is in resonance with the $3 d^{5} 4 s^{2} \rightarrow 3 d^{5} 4 s 4 p$ transition of Mn at $279.5 \mathrm{~nm}$, a clear signal appears at $m / z=55$, nearly as high as the peak of the much more abundant ${ }^{56} \mathrm{Fe}$ in the sum spectrum; see Fig. 3b. Additionally, for Zn (mass fraction $0.17 \%$ ) there is a substantial difference and a clear signature appears in resonance case (Fig. 3c). Because the resonance wavelength of $213.8 \mathrm{~nm}$ is near the UV limit of the OPO, the pulse energy of $0.25 \mathrm{~mJ}$ is lower than for the other metals and, in contrast to all other wavelength comparisons, the reference wavelength is higher than the resonance wavelength. After resonant excitation at the respec- 

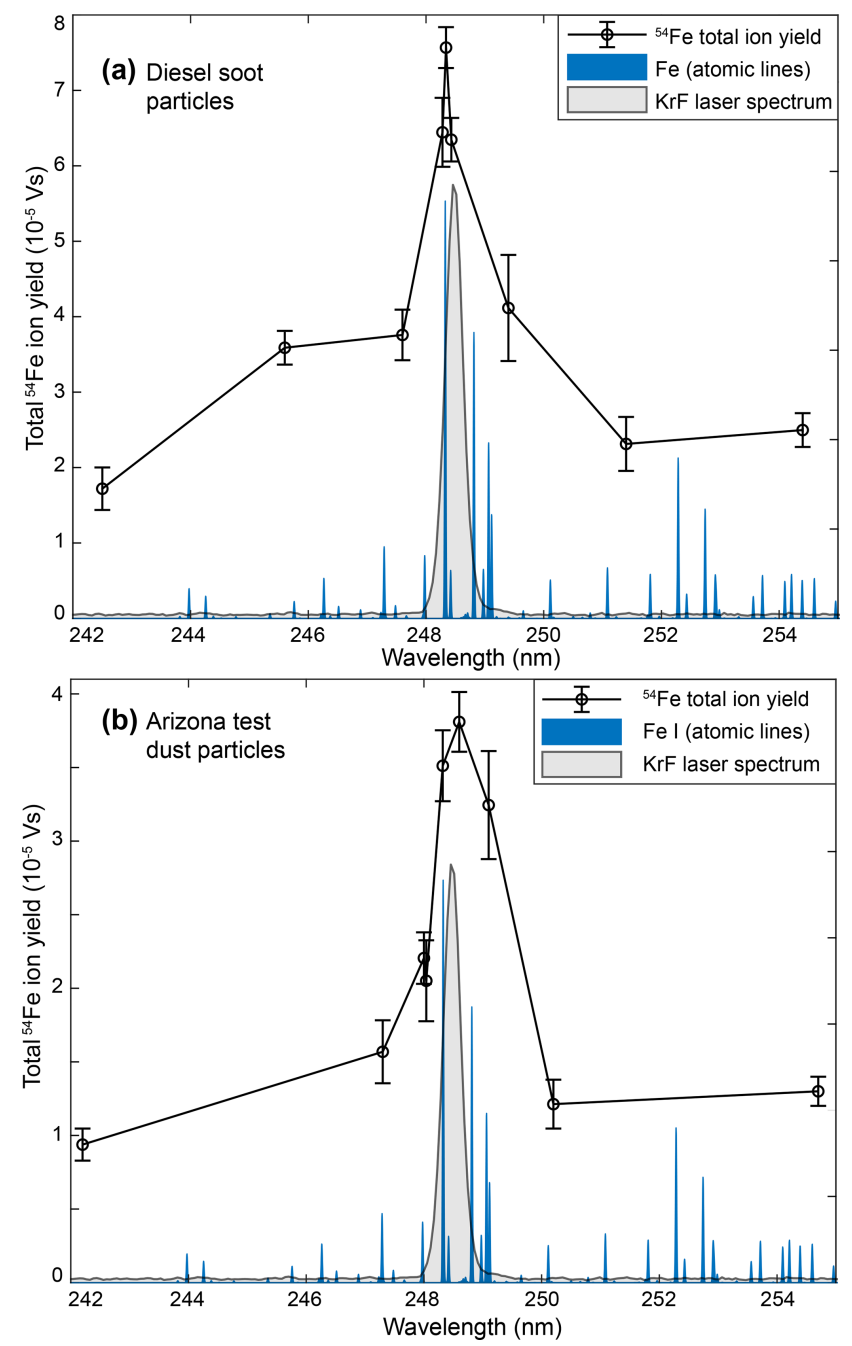

Figure 2. Wavelength-dependent total ion yield of ${ }^{54} \mathrm{Fe}$ in SPMS of re-dispersed particles (black circles, $n=1200$; three replicates of 400 each). For both (a) diesel soot particles and (b) Arizona desert dust particles, the signal peaks for wavelengths match a major atomic transition of $\mathrm{Fe}$ (blue lines). The large width of the curve is attributed to line broadening through interaction with the dense particle surface. Coincidentally, the Fe lines are also addressed by our KrF-excimer laser (measured spectrum in grey; arbitrary units). Atomic spectra from the NIST library (Kramida et al., 2019). Mass spectra are shown in Fig. 1, the respective curves of the normalized ion signals and size distributions are given in Fig. S3.

tive wavelength, the absorption of a further single photon is sufficient for ionization of all three metals. The histogram plots (Fig. 3d-f) prove that the enhancement does not only result from a minority of particles that contribute especially strong ion signals. In contrast, a higher number of individual particles reveal signatures of the respective metals, which indicates a more secure and sensitive detection. The results suggest that tuneable laser systems can be advantageous to enhance the detectability of various elements of interest in SPMS.

\subsection{Application to long-range transported aerosols}

While our laboratory experiments revealed remarkable resonance effects for several metals and particle types, these results have to be transferred into applications for ambient aerosols. Tuneable laser systems are of limited suitability for field studies because of their complexity, low pulse power and repetition rate. In our experiments, thermal lensing problems of the irregularly triggered OPO system reduced its pulse power and stability, resulting in a shot-to-shot variability of the pulse power up to about $30 \%$. However, a freely triggerable OPO-SPMS with sufficient pulse energy is under development. In contrast to tuneable light sources, excimer lasers are cheaper, more robust and powerful. Of note, the $\mathrm{KrF}$-excimer laser line at $248.3 \mathrm{~nm}$ coincidentally matches the strongest UV absorption line of $\mathrm{Fe}$, a fact that has gained little attention in the last few decades (Trainor and Mani, 1978; Seder et al., 1986). The spectrum of our laser is shown in Fig. 2. We directly compare the Fe detection efficiencies of two field-deployable excimer lasers for the same ambient aerosol ensemble. The $\mathrm{KrF}$ line is in resonance with the Fe absorption, while the often-used ArF line is not. To exclude all effects from different instrumentation, both lasers are integrated into the same SPMS, firing with the same pulse parameters from opposite sites onto the particles; see Fig. 4a and Table 1. A custom electronic circuit triggers the lasers alternately. With regard to the important application of detecting Fe-containing aerosols in remote regions, we designed our experiment to observe long-range transported anthropogenic particles with high secondary contributions in a marine environment. Therefore, we set up our instrument on the western coast of Sweden and measured aerosols from central Europe after transport over the Baltic Sea; see the back trajectories in Fig. 4b.

With each of the lasers, we analyzed 15000 individual particles on the 14 November 2019 between 15:00 and 24:00 local time. The mean particle mass concentration was $7.8 \mu \mathrm{g} \mathrm{m}^{-3}\left(\mathrm{PM}_{2.5}\right)$ and $5.0 \mu \mathrm{g} \mathrm{m}^{-3}\left(\mathrm{PM}_{1.0}\right)$ as measured by the station's dust monitor (Grimm EDM-180 MC). Figure 4c shows the resulting sum mass spectra of cations for each ionization wavelength. The enhanced $\mathrm{Fe}$ signature for the Krf laser is clearly visible in the sum spectrum. All further wavelength-dependent differences will be discussed in a future publication. From every 15000 particles exposed to the ArF laser (KrF laser), 13776 (6364) produced a negative spectrum, 12217 (5577) a positive signature and 12189 (5258) yielded bipolar mass spectra. The higher hit rate of the ArF laser results from the lower intensity thresholds for ion formation due to its higher photon energy (Thomson et al., 1997), thus also yielding mass spectra from particles that were not fully hit. Nearly all particles $(>98 \%)$ with negative spectra showed nitrate $\left({ }^{46} \mathrm{NO}_{2}^{-}\right.$and $\left.{ }^{62} \mathrm{NO}_{3}^{-}\right)$. Because the steady onshore wind during the experiment excludes local sources of nitrate, these ions indicate condensation of $\mathrm{NO}_{3}$ and replacement of $\mathrm{Cl}^{-}$by $\mathrm{NO}_{3}^{-}$(Gard et 

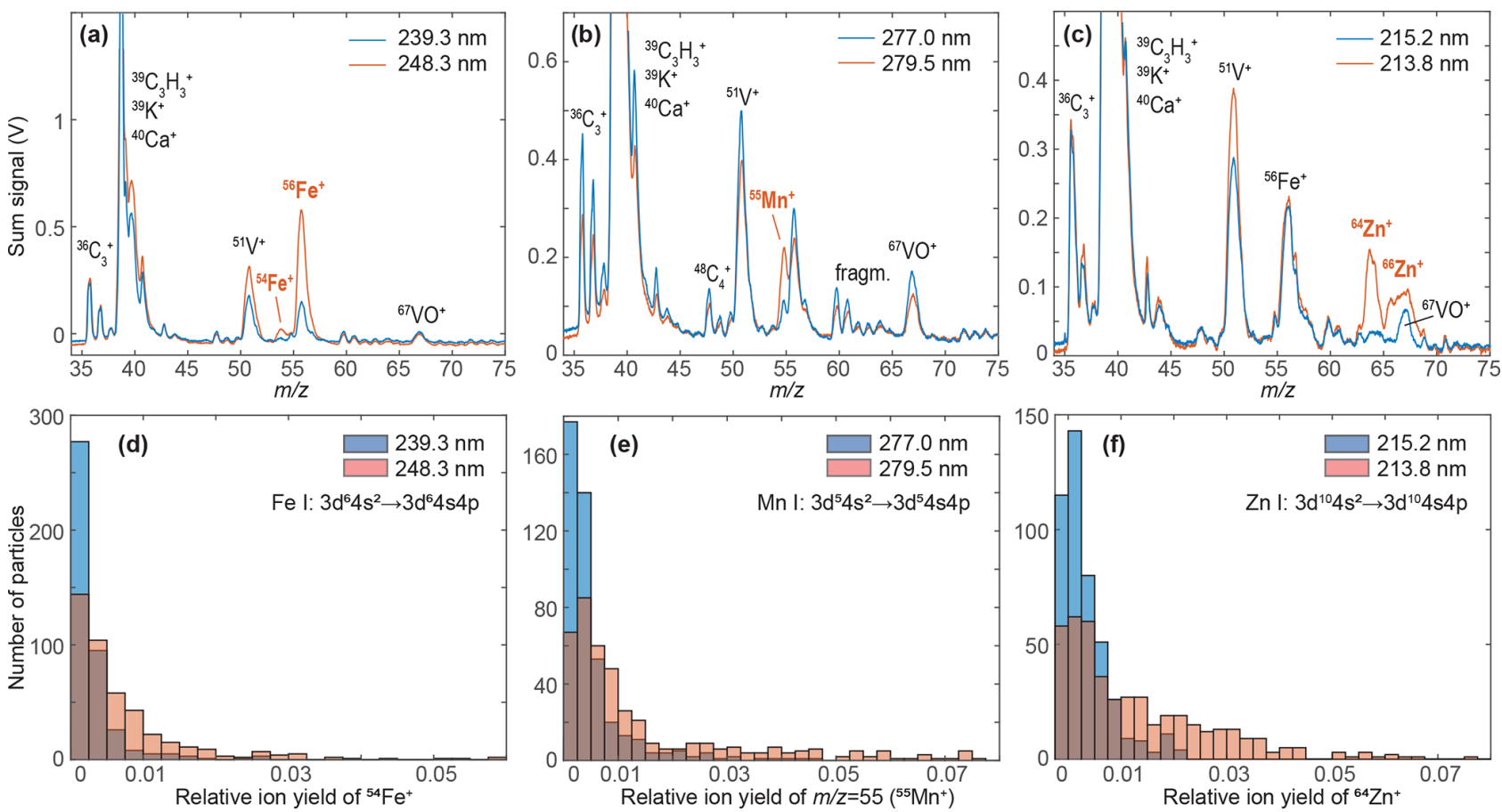

Figure 3. Accumulated cation mass spectra $(n=400)$ of re-dispersed urban dust particles (reference material NIST 1649b). Using the tuneable OPO, the spectra were recorded at resonance wavelengths of each metal (red) and for the nonresonant case at a slightly different wavelength (blue). While carbon and molecular fragment signals are similar in the pairwise comparison, the resonant enhancements for (a) Fe, (b) $\mathrm{Mn}$ and (c) $\mathrm{Zn}$ are clearly visible. Complete bipolar mass spectra and the size distribution are shown in Fig. S5. (d-f) The singleparticle distribution of the relative ion signals illustrates that the resonant ionization enhancement allows metal detection for many more particles. The respective resonance wavelengths (red) address the indicated transitions.
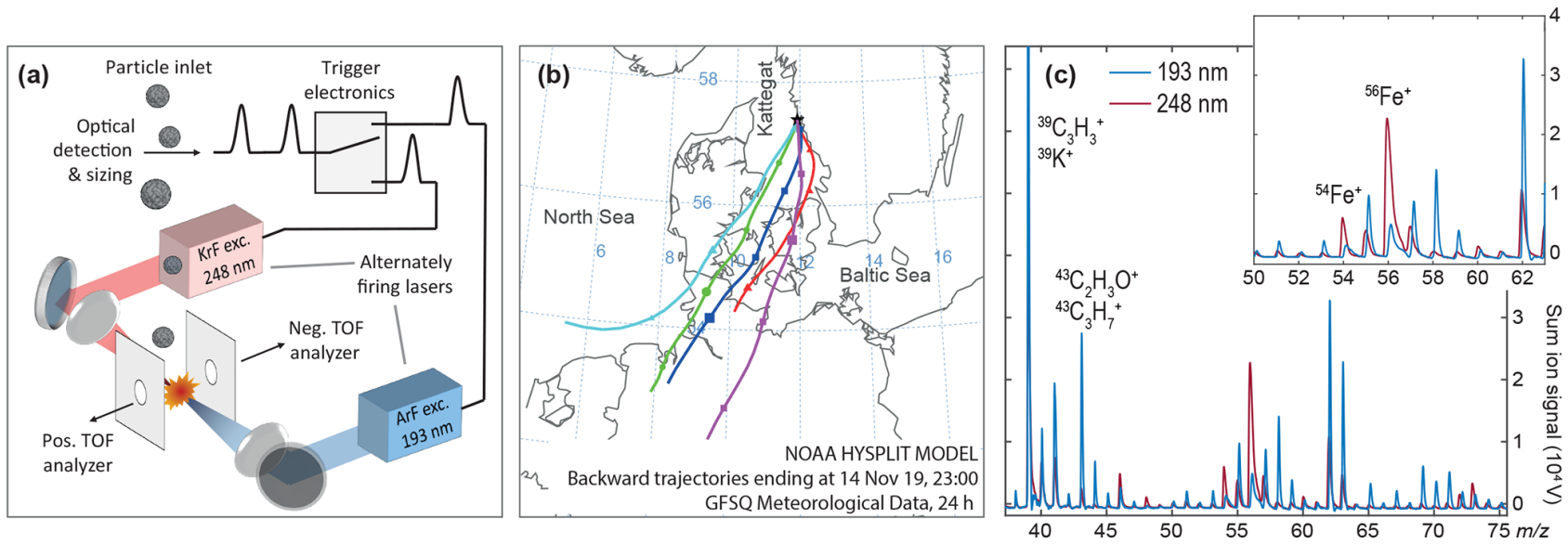

Figure 4. (a) Schematic view of the setup for direct comparison of nonresonant and resonant ionization of Fe in ambient air particles using the same mass spectrometer. The two lasers fired alternately on 15000 particles each. (b) Back trajectories from the HYSPLIT webtool (http://www.ready.noaa.gov/HYSPLIT.php, last access: 13 December 2019) (Stein et al., 2015; Rolph et al., 2017), ending at the sampling site (sea level) during the experiment on long-range transported particles. (c) Accumulated cation mass spectra (every $n=15000)$ show a $\mathrm{Fe}^{+}$-signal enhancement for ionization with the $\mathrm{KrF}$ excimer laser $(248 \mathrm{~nm}$, red) versus the ArF excimer laser (193 nm, blue). Further differences will be discussed in a different publication. 
al., 1998; Arndt et al., 2017; Dall'Osto et al., 2016b) during long-range transport from central Europe (Dall'Osto et al., 2016a). Most single-particle spectra are dominated by either sea salt signatures $\left({ }^{23} \mathrm{Na}^{+},{ }^{46} \mathrm{Na}_{2}^{+},{ }^{62} \mathrm{Na}_{2} \mathrm{O}^{+},{ }^{63} \mathrm{Na}_{2} \mathrm{OH}^{+}\right.$and ${ }^{81,83} \mathrm{Na}_{2} \mathrm{Cl}^{+}$) (Murphy et al., 2019) or organic fragments (e.g., ${ }^{27} \mathrm{C}_{2} \mathrm{H}_{3}^{+},{ }^{39} \mathrm{C}_{3} \mathrm{H}_{3}^{+},{ }^{43} \mathrm{C}_{2} \mathrm{H}_{3} \mathrm{O}^{+}$and ${ }^{43} \mathrm{C}_{3} \mathrm{H}_{7}^{+}$) (Silva and Prather, 2000) or they reveal internal mixtures of these main components. To investigate the $\mathrm{Fe}$ enhancements on the single-particle level and to analyze the role of the particle's main components, we performed a cluster analysis for each set of bipolar single-particle spectra, excluding the mass channels $m / z=54-56$ that bear potential Fe signatures. The ART-2a algorithm yielded 149 clusters for the particles ionized with the ArF laser and 106 clusters for the $\mathrm{KrF}$ laser ionization. Clusters with less than 20 particles were excluded from the analysis. Furthermore, clusters with comparable average mass spectra and the same major ions but slightly varying relative signal intensities were manually merged.

The particle ensemble revealed six dominating particle groups, as summarized in Table 2. The corresponding ART$2 \mathrm{a}$ area matrices representing the average intensity for each $\mathrm{m} / \mathrm{z}$ and thus reflecting the typical mass spectra within a group are shown in Figs. S6 and S7. Further separation into subgroups, e.g., with respect to signals from ${ }^{18} \mathrm{NH}_{4}^{+},{ }^{30} \mathrm{NO}^{+}$ or trimethylamine (TMA, $m / z=58-59$ ) (Healy et al., 2015; Köllner et al., 2017), had only limited effects on Fe detection and is consequently not shown here. Mineral dust particles were not observed in appreciable numbers. The measured size distribution is rather narrow, reflecting the instruments optimum detection efficiency that roughly coincides with the typical size mode undergoing long-range transport; see Fig. S8.

The particle numbers within the main classes are shown in Fig. 5. There are several differences between the two ionization wavelengths, e.g., the aforementioned overall hit rate. However, here we focus on the detection of Fe. In order to ensure a conservative effect registration (i.e., signals at $m / z=56$ that may also stem from $\mathrm{CaO}^{+}$or molecular fragments such as $\mathrm{C}_{3} \mathrm{H}_{4} \mathrm{O}^{+}$), $\mathrm{Fe}$ content is only accounted for particles with a peak area at $m / z=56$ that is larger than both the signals at $m / z=40\left(\mathrm{Ca}^{+}\right)$and $m / z=55$ (principal fragment signal). To further strengthen the screening, as recommended by previous studies (Zhang et al., 2014; Dall'Osto et al., 2016a), particles with an additional signal at $m / z=54$ from the ${ }^{54} \mathrm{Fe}$ isotope, which is lower than a tenth of the peak area of ${ }^{56} \mathrm{Fe}$, are represented by black bars. Half of the particle spectra that were identified by the algorithm to show the ${ }^{54} \mathrm{Fe}$ isotope, were manually cross-checked on a random basis to prevent false positive results. From the 15000 particles exposed to the $193 \mathrm{~nm}$ laser pulses, fewer than 100 particles show $\mathrm{Fe}$ signatures according to this stringent criterion. As is apparent from the enlarged view on the right of Fig. 5a, nearly all of these particles also revealed strong carbon cluster signals from EC. This suggests that they either belong to a particular Fe-rich aerosol class, e.g., from ship emis-

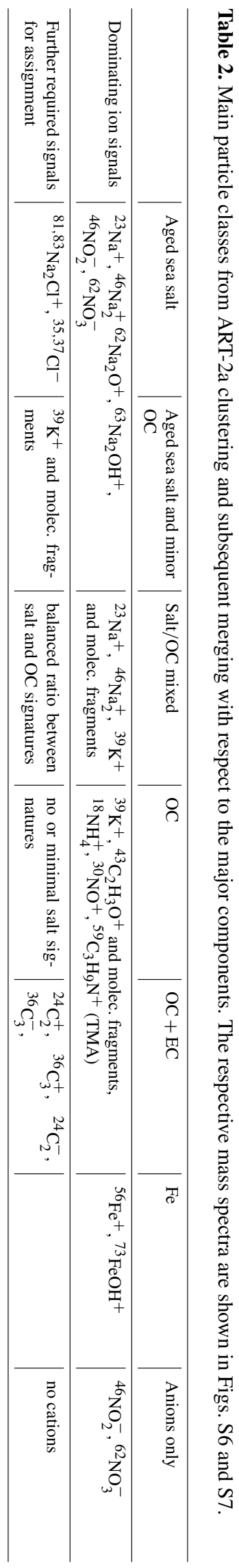

https://doi.org/10.5194/acp-20-7139-2020 


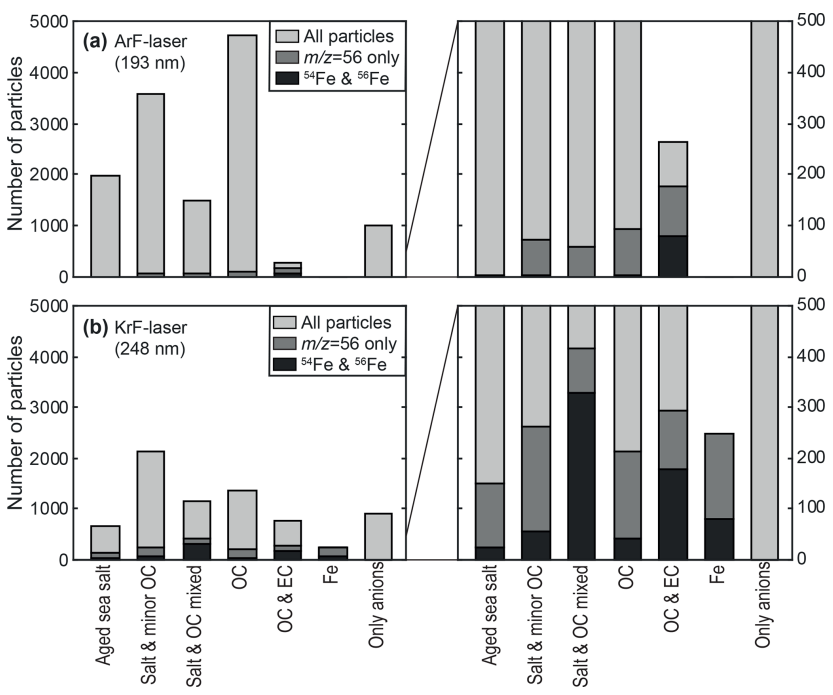

Figure 5. Number of particles within the main classes according to Table 2. Dark grey fractions represent particles with a peak area at $m / z=56$ being larger than at $m / z=55$ (molecular fragments) and $m / z=40\left(\mathrm{Ca}^{+}\right.$because of interference with $\left.{ }^{56} \mathrm{CaO}^{+}\right)$, indicating Fe content. Black fractions illustrate particles showing an additional signal of the less abundant isotope ${ }^{54} \mathrm{Fe}^{+}$. (a) If ionized with $193 \mathrm{~nm}$ pulses, substantial fragmentation leads to dominating fragment signals in many of the 15000 exposed particles. Fe signals are almost exclusively observed for particles with EC signatures (see the enlarged view on the right), indicating a particularly high $\mathrm{Fe}$ content or possible interactions with strongly absorbing soot during ionization. (b) Although fewer particles produce ion signals if exposed to $248 \mathrm{~nm}$ pulses, the particle fraction showing Fe signatures is much larger, and a cluster with dominating Fe signals even appears. It is important to note that the Fe signals are not limited to EC-containing particles but can be observed for all classes. This suggests that the resonant ionization allows a more universal and secure detection of Fe.

sions, or that the EC matrix augments the ionization process of Fe (Zimmermann et al., 2003) in contrast to a salt/OC matrix, where energetically preferred ions survive collisional charge transfer in the plume (Reinard and Johnston, 2008). Additionally, a suppression of specific ions by the presence of water is conceivable (Neubauer et al., 1998), although a dryer was applied in our experiment. A very different Fe detection was achieved with the resonant ionization at $248 \mathrm{~nm}$; see Fig. 5b. Even though the total particle hit rate was lower, many more particles with Fe signatures were detected. A key finding is that the Fe detection is not limited to particles with EC signatures anymore, but the Fe appears to be internally mixed within particles of several classes. The relatively low abundance of Fe in the OC class can be explained by the high contribution of wood and biomass combustion particles. Remarkably, many particles with low cation signals reveal nearly exclusively Fe signatures, providing its own group after further classification into subgroups (Fe signatures were excluded from the first ART-2a clustering).
Since the same aerosol ensemble was probed with both laser wavelengths, the appearance of $\mathrm{Fe}$ signals for several particle matrices disagrees with the assumption of a particular Fe-rich class. In contrast, different ionization mechanisms are likely to determine the Fe detection, and resonant LDI appears to feature a more universal and secure detection approach for iron.

Although our field study provides only a limited dataset, some general implications can already be derived. The internal mixing of $\mathrm{Fe}$ with sulfate or organic acids is assumed to be crucial for Fe dissolution and thus for the anthropogenic increase in bioavailable iron input to the oceans ( $\mathrm{Li}$ et al., 2017). Previous studies indicated that the Fe transport into the sea is dominated by coal combustion particles containing sulfate in Asia (Furutani et al., 2011; Moffet et al., 2012), while the majority of Fe-containing particles in Europe are mixed with nitrate and were attributed to traffic activities (Dall'Osto et al., 2016a). Similar to our experiment, these studies found strong internal mixing of many Fe-containing particles, such as biomass burning signals with coal combustion contributions in Asia and secondary nitrate with $\mathrm{Fe}$ in Europe. However, Fe particles with sea salt signatures were negligible in the SPMS studies and mixtures of Fe and OC were a minor fraction (Furutani et al., 2011; Dall'Osto et al., 2016a). In our study, these particles were the most abundant types of Fe-containing particles if resonant ionization was applied (see Fig. 5b), while for nonresonant ionization, particles with EC signatures were dominant (Fig. 5a). Taking into account that the aforementioned SPMS studies utilized nonresonant LDI of Fe at $266 \mathrm{~nm}, \mathrm{Fe}$ transport in organic and salt or mixed aerosols might have been underestimated. Electron microscopy studies of individual particles in Asia frequently revealed thick coatings of secondary compounds and organic matter around Fe-rich particle components (Li et al., 2017; Moffet et al., 2012). Ultrafine Fe-containing particles, such as soot from traffic emissions, can enter the long-range transported accumulation mode via agglomeration with larger particles and condensation of organic vapors, secondary nitrate or sulfate. In our study, we observed a high prevalence of $\mathrm{Fe}$ in sea salt and OC particle types, indicating the importance of these pathways for transport of biologically relevant Fe.

\section{Conclusions}

In summary, we described enhancements in particle laser desorption-ionization that rely on resonant light absorption by metal atoms. Combining laboratory and field experiments, we showed that the mechanism can be exploited to improve the detection of relevant metals in both natural and anthropogenic aerosols on the single-particle level. Not all physical details are fully understood, and the signal enhancement effects providing the basis for the improved metal detection efficiency are difficult to quantify for the different particle types. However, our results show that the increase in sensi- 
tivity is moderate for particular Fe-rich aerosols, such as the about 3-fold signal enhancement for Arizona test dust. The resonance enhancement appears to become more effective for mixed particles with smaller Fe contributions, such as in the ambient air experiment, where about 10 times more particles revealed $\mathrm{Fe}$ signatures in direct comparison with nonresonant ionization. Taking into account the lower hit rate of the $\mathrm{KrF}$ laser that is related to its lower photon energy, the overall efficiency for identifying Fe signatures in a single-particle mass spectrum was increased by a factor of about 20 in our ambient air study.

The coincidental matching of the $\mathrm{KrF}$ laser line with a strong absorption of Fe atoms allows an easy and straightforward application of the resonance effect in the field. For direct comparison of $\mathrm{KrF}$ with ArF lasers, it has to be considered that the lower photon energy of $\mathrm{KrF}$ laser is associated with a reduced hit rate and different mass spectral signatures of other particle components, e.g., organics. Further studies are required to evaluate these differences. Note that, because of its rather high pulse energy and the flat-top beam profile, the hit rate of the $\mathrm{KrF}$ laser was about $40 \%-50 \%$ in our experiment, which is still more than the values that are typically achieved with the most common laser line in SPMS, the Nd:YAG at $266 \mathrm{~nm}$. Exploiting the resonance effect for metals other than $\mathrm{Fe}$ requires a tuneable Nd:YAG-OPO system, which is, however, more difficult to operate.

With the improved detection of Fe and its inherent sensitivity to further key nutrients such as nitrate and phosphate, SPMS becomes an interesting complement to established methods for investigating atmospheric $\mathrm{Fe}$ transport. Moreover, several key parameters for the metal's bioavailability, including the particle size or the presence of carboxylic acids and sulfate (Fang et al., 2017), can be determined on a singleparticle level. Because of the high time resolution, SPMSbased $\mathrm{Fe}$ detection may be particularly helpful for studies on the oceans' rapid response to the naturally episodic depositions of $\mathrm{Fe}$ and other micronutrients. Beyond these direct applications, more studies are required to elucidate the promising implications for SPMS quantification approaches (Healy et al., 2013; Gemayel et al., 2017). Of note, the Fe-containing particles can further be characterized with regard to their organic content using multistep ionization techniques (Schade et al., 2019; Czech et al., 2017). This is of importance for health-related studies, as two of the most relevant adverse aerosol compounds, transition metals and PAHs, can be addressed with the same easily accessible KrF-excimer laser wavelength.

Such hyphenated single-particle schemes have great potential to elucidate intriguing interactions in atmospheric heterogeneous and multiphase chemistry (Pöschl and Shiraiwa, 2015), for example with regard to possible catalytic activities of the in particle's metal content (Sullivan et al., 2007). In conclusion, the described resonance effects pave a new route towards improved detection of air pollutants and a more pro- found understanding of the aerosol impact on biogeochemical cycles and human health.

Data availability. Data are available on request from Johannes Passig (johannes.passig@uni-rostock.de).

Supplement. The supplement related to this article is available online at: https://doi.org/10.5194/acp-20-7139-2020-supplement.

Author contributions. JP and JS contributed equally to this work. JP conceived the experiments. JS, EIR, JP, TKB and RI performed the experiments. LL, XL and ZZ provided the SPMS instrument and technical support. TKB developed the electronics. HC, MS, TS and $\mathrm{RZ}$ provided assistance with data interpretation. JM and HF hosted and supported the field study. JS, JP and EIR analyzed data and prepared the figures. JP wrote the manuscript with contributions from all authors.

Competing interests. The authors declare that they have no conflict of interest.

Acknowledgements. We thank Johan Mellqvist, John Conway, Lars Eriksson and co-workers from the Chalmers University of Technology and from the IVL Miljöinstitut for hosting the field experiments and their support.

The authors gratefully acknowledge the NOAA Air Resources Laboratory (ARL) for the provision of the HYSPLIT transport and dispersion model and READY website (https://www.ready.noaa. gov, last access: 13 December 2019) used in this publication.

Financial support. This research has been supported by the Deutsche Forschungsgemeinschaft (grant no. ZI 764/6-1), the Bundesministerium für Wirtschaft und Energie (grant no. ZF4402101 ZG7), the Helmholtz-Gemeinschaft (International Lab AeroHealth), and the Helmholtz Virtual Institute of Complex Molecular Systems in Environmental Health (HICE).

Review statement. This paper was edited by Harald Saathoff and reviewed by two anonymous referees.

\section{References}

Arndt, J., Sciare, J., Mallet, M., Roberts, G. C., Marchand, N., Sartelet, K., Sellegri, K., Dulac, F., Healy, R. M., and Wenger, J. C.: Sources and mixing state of summertime background aerosol in the north-western Mediterranean basin, Atmos. Chem. Phys., 17, 6975-7001, https://doi.org/10.5194/acp17-6975-2017, 2017.

Ault, A. P., Gaston, C. I., Wang, Y., Dominguez, G., Thiemens, M. H., and Prather, K. A.: Characterization of the single par- 
ticle mixing state of individual ship plume events measured at the Port of Los Angeles, Environ. Sci. Technol., 44, 1954-1961, https://doi.org/10.1021/es902985h, 2010.

Bente, M., Sklorz, M., Streibel, T., and Zimmermann, R.: Online laser desorption-multiphoton postionization mass spectrometry of individual aerosol particles: molecular source indicators for particles emitted from different traffic-related and wood combustion sources, Anal. Chem., 80, 8991-9004, https://doi.org/10.1021/ac801295f, 2008.

Bente, M., Sklorz, M., Streibel, T., and Zimmermann, R.: Thermal desorption-multiphoton ionization time-of-flight mass spectrometry of individual aerosol particles: a simplified approach for online single-particle analysis of polycyclic aromatic hydrocarbons and their derivatives, Anal. Chem., 81, 2525-2536, https://doi.org/10.1021/ac802296f, 2009.

Bond, T. C., Doherty, S. J., Fahey, D. W., Forster, P. M., Berntsen, T., DeAngelo, B. J., Flanner, M. G., Ghan, S., Kärcher, B., Koch, D., Kinne, S., Kondo, Y., Quinn, P. K., Sarofim, M. C., Schultz, M. G., Schulz, M., Venkataraman, C., Zhang, H., Zhang, S., Bellouin, N., Guttikunda, S. K., Hopke, P. K., Jacobson, M. Z., Kaiser, J. W., Klimont, Z., Lohmann, U., Schwarz, J. P., Shindell, D., Storelvmo, T., Warren, S. G., and Zender, C. S.: Bounding the role of black carbon in the climate system: A scientific assessment, J. Geophys. Res., 118, 5380-5552, https://doi.org/10.1002/jgrd.50171, 2013.

Boyd, P. W., Ellwood, M. J., Tagliabue, A., and Twining, B. S.: Biotic and abiotic retention, recycling and remineralization of metals in the ocean, Nat. Geosci., 10, 167-173, https://doi.org/10.1038/ngeo2876, 2017.

Carson, P. G., Johnston, M. V., and Wexler, A. S.: RealTime Monitoring of the Surface and Total Composition of Aerosol Particles, Aerosol Sci. Technol., 26, 291-300, https://doi.org/10.1080/02786829708965431, 1997.

Conway, T. M., Hamilton, D. S., Shelley, R. U., Aguilar-Islas, A. M., Landing, W. M., Mahowald, N. M., and John, S. G.: Tracing and constraining anthropogenic aerosol iron fluxes to the North Atlantic Ocean using iron isotopes, Nat. Commun., 10, 1-10, https://doi.org/10.1038/s41467-019-10457-w, 2019.

Czech, H., Stengel, B., Adam, T., Sklorz, M., Streibel, T., and Zimmermann, R.: A chemometric investigation of aromatic emission profiles from a marine engine in comparison with residential wood combustion and road traffic: Implications for source apportionment inside and outside sulphur emission control areas, Atmos. Environ., 167, 212-222, https://doi.org/10.1016/j.atmosenv.2017.08.022, 2017.

Dall'Osto, M., Harrison, R. M., Highwood, E. J., O’Dowd, C., Ceburnis, D., Querol, X., and Achterberg, E. P.: Variation of the mixing state of Saharan dust particles with atmospheric transport, Atmos. Environ., 44, 3135-3146, https://doi.org/10.1016/j.atmosenv.2010.05.030, 2010.

Dall'Osto, M., Beddows, D. C. S., Harrison, R. M., and Onat, B.: Fine Iron Aerosols Are Internally Mixed with Nitrate in the Urban European Atmosphere, Environ. Sci. Technol., 50, 42124220, https://doi.org/10.1021/acs.est.6b01127, 2016a.

Dall'Osto, M., Beddows, D. C. S., McGillicuddy, E. J., Esser-Gietl, J. K., Harrison, R. M., and Wenger, J. C.: On the simultaneous deployment of two single-particle mass spectrometers at an urban background and a roadside site during SAPUSS, At- mos. Chem. Phys., 16, 9693-9710, https://doi.org/10.5194/acp16-9693-2016, 2016b.

Fang, T., Guo, H., Zeng, L., Verma, V., Nenes, A., and Weber, R. J.: Highly Acidic Ambient Particles, Soluble Metals, and Oxidative Potential: A Link between Sulfate and Aerosol Toxicity, Environ. Sci. Technol., 51, 2611-2620, https://doi.org/10.1021/acs.est.6b06151, 2017.

Fergenson, D. P., Song, X. H., Ramadan, Z., Allen, J. O., Hughes, L. S., Cass, G. R., Hopke, P. K., and Prather, K. A.: Quantification of ATOFMS data by multivariate methods, Anal. Chem., 73, 35353541, https://doi.org/10.1021/ac010022j, 2001.

Furutani, H., Jung, J., Miura, K., Takami, A., Kato, S., Kajii, Y., and Uematsu, M.: Single-particle chemical characterization and source apportionment of iron-containing atmospheric aerosols in Asian outflow, J. Geophys. Res., 116, 5504, https://doi.org/10.1029/2011JD015867, 2011.

Gard, E. E., Kleeman, M. J., Gross, D. S., Hughes, L. S., Allen, J. O., Morrical, B. D., Fergenson, D. P., Dienes, T., Gälli, M. E., Johnson, R. J., Cass, G. R., and Prather, K. A.: Direct observation of heterogeneous chemistry in the atmosphere, Science, 279, 1184-1187, https://doi.org/10.1126/science.279.5354.1184, 1998.

Gaur, S. and Agnihotri, R.: Health Effects of Trace Metals in Electronic Cigarette Aerosols-a Systematic Review, Biol. Trace Elem. Res., 188, 295-315, https://doi.org/10.1007/s12011-0181423-x, 2019.

Gemayel, R., Temime-Roussel, B., Hayeck, N., Gandolfo, A., Hellebust, S., Gligorovski, S., and Wortham, H.: Development of an analytical methodology for obtaining quantitative mass concentrations from LAAP-ToF-MS measurements, Talanta, 174, 715-724, https://doi.org/10.1016/j.talanta.2017.06.050, 2017.

Gonzalez, C. A. and Choquette, S. J.: Certificate of Analysis: Standard Reference Material 1649b, available at: https://www-s.nist. gov/srmors/certificates/1649b.pdf, last access: 23 April 2020.

Gross, D. S., Gälli, M. E., Silva, P. J., and Prather, K. A.: Relative Sensitivity Factors for Alkali Metal and Ammonium Cations in Single-Particle Aerosol Time-of-Flight Mass Spectra, Anal. Chem., 72, 416-422, https://doi.org/10.1021/ac990434g, 2000.

Gunzer, F., Krüger, S., and Grotemeyer, J.: Photoionization and photofragmentation in mass spectrometry with visible and UV lasers, Mass Spectrom. Rev., 38, 202-217, https://doi.org/10.1002/mas.21579, 2019.

Hatch, L. E., Pratt, K. A., Huffman, J. A., Jimenez, J. L., and Prather, K. A.: Impacts of Aerosol Aging on Laser Desorption/Ionization in Single-Particle Mass Spectrometers, Aerosol Sci. Technol., 48, 1050-1058, https://doi.org/10.1080/02786826.2014.955907, 2014.

Healy, R. M., O'Connor, I. P., Hellebust, S., Allanic, A., Sodeau, J. R., and Wenger, J. C.: Characterisation of single particles from in-port ship emissions, Atmos. Environ., 43, 6408-6414, https://doi.org/10.1016/j.atmosenv.2009.07.039, 2009.

Healy, R. M., Sciare, J., Poulain, L., Crippa, M., Wiedensohler, A., Prévôt, A. S. H., Baltensperger, U., Sarda-Estève, R., McGuire, M. L., Jeong, C.-H., McGillicuddy, E., O’Connor, I. P., Sodeau, J. R., Evans, G. J., and Wenger, J. C.: Quantitative determination of carbonaceous particle mixing state in Paris using single-particle mass spectrometer and aerosol mass spectrometer measurements, Atmos. Chem. Phys., 13, 9479-9496, https://doi.org/10.5194/acp-13-9479-2013, 2013. 
Healy, R. M., Evans, G. J., Murphy, M., Sierau, B., Arndt, J., McGillicuddy, E., O'Connor, I. P., Sodeau, J. R., and Wenger, J. C.: Single-particle speciation of alkylamines in ambient aerosol at five European sites, Anal. Bioanal. Chem., 407, 5899-5909, https://doi.org/10.1007/s00216-014-8092-1, 2015.

Hinz, K.-P. and Spengler, B.: Instrumentation, data evaluation and quantification in on-line aerosol mass spectrometry, J. Mass Spectrom., 42, 843-860, https://doi.org/10.1002/jms.1262, 2007.

Hübert, W. and Ankerhold, G.: Elemental misinterpretation in automated analysis of LIBS spectra, Analytical and bioanalytical chemistry, 400, 3273-3278, https://doi.org/10.1007/s00216-0114793-x, 2011.

Ito, A.: Atmospheric Processing of Combustion Aerosols as a Source of Bioavailable Iron, Environ. Sci. Technol. Lett., 2, 7075, https://doi.org/10.1021/acs.estlett.5b00007, 2015.

Ito, A. and Shi, Z.: Delivery of anthropogenic bioavailable iron from mineral dust and combustion aerosols to the ocean, Atmos. Chem. Phys., 16, 85-99, https://doi.org/10.5194/acp-16-852016, 2016.

Jickells, T. D., An, Z. S., Andersen, K. K., Baker, A. R., Bergametti, G., Brooks, N., Cao, J. J., Boyd, P. W., Duce, R. A., Hunter, K. A., Kawahata, H., Kubilay, N., laRoche, J., Liss, P. S., Mahowald, N., Prospero, J. M., Ridgwell, A. J., Tegen, I., and Torres, R.: Global iron connections between desert dust, ocean biogeochemistry, and climate, Science, 308, 67-71, https://doi.org/10.1126/science.1105959, 2005.

Kanakidou, M., Seinfeld, J. H., Pandis, S. N., Barnes, I., Dentener, F. J., Facchini, M. C., Van Dingenen, R., Ervens, B., Nenes, A., Nielsen, C. J., Swietlicki, E., Putaud, J. P., Balkanski, Y., Fuzzi, S., Horth, J., Moortgat, G. K., Winterhalter, R., Myhre, C. E. L., Tsigaridis, K., Vignati, E., Stephanou, E. G., and Wilson, J.: Organic aerosol and global climate modelling: a review, Atmos. Chem. Phys., 5, 1053-1123, https://doi.org/10.5194/acp-5-10532005, 2005.

Kanashova, T., Sippula, O., Oeder, S., Streibel, T., Passig, J., Czech, H., Kaoma, T., Sapcariu, S. C., Dilger, M., Paur, H.-R., Schlager, C., Mülhopt, S., Weiss, C., Schmidt-Weber, C., Traidl-Hoffmann, C., Michalke, B., Krebs, T., Karg, E., Jakobi, G., Scholtes, S., Schnelle-Kreis, J., Sklorz, M., Orasche, J., Müller, L., Reda, A., Rüger, C., Neumann, A., Abbaszade, G., Radischat, C., Hiller, K., Grigonyte, J., Kortelainen, M., Kuuspalo, K., Lamberg, H., Leskinen, J., Nuutinen, I., Torvela, T., Tissari, J., Jalava, P., Kasurinen, S., Uski, O., Hirvonen, M.-R., Buters, J., Dittmar, G., Jokiniemi, J. K., and Zimmermann, R.: Emissions from a modern log wood masonry heater and wood pellet boiler Composition and biological impact on air-liquid interface exposed human lung cancer cells, Journal of Molecular and Clinical Medicine, 1, 23, https://doi.org/10.31083/j.jmcm.2018.01.004, 2018.

Köllner, F., Schneider, J., Willis, M. D., Klimach, T., Helleis, F., Bozem, H., Kunkel, D., Hoor, P., Burkart, J., Leaitch, W. R., Aliabadi, A. A., Abbatt, J. P. D., Herber, A. B., and Borrmann, S.: Particulate trimethylamine in the summertime Canadian high Arctic lower troposphere, Atmos. Chem. Phys., 17, 1374713766, https://doi.org/10.5194/acp-17-13747-2017, 2017.

Kramida, A., Ralchenko, Yu., Reader, J., and NIST ASD Team: NIST Atomic Spectra Database (version 5.7.1), National Institute of Standards and Technology, Gaithersburg, MD, https://doi.org/10.18434/T4W30F, 2019.
Laskin, J., Laskin, A., and Nizkorodov, S. A.: Mass Spectrometry Analysis in Atmospheric Chemistry, Anal. Chem., 90, 166-189, https://doi.org/10.1021/acs.analchem.7b04249, 2018.

Li, C., He, Q., Schade, J., Passig, J., Zimmermann, R., Meidan, D., Laskin, A., and Rudich, Y.: Dynamic changes in optical and chemical properties of tar ball aerosols by atmospheric photochemical aging, Atmos. Chem. Phys., 19, 139-163, https://doi.org/10.5194/acp-19-139-2019, 2019.

Li, L., Huang, Z., Dong, J., Li, M., Gao, W., Nian, H., Fu, Z., Zhang, G., Bi, X., Cheng, P., and Zhou, Z.: Real time bipolar time-of-flight mass spectrometer for analyzing single aerosol particles, Int. J. Mass Spectrom., 303, 118-124, https://doi.org/10.1016/j.ijms.2011.01.017, 2011.

Li, L., Liu, L., Xu, L., Li, M., Li, X., Gao, W., Huang, Z., and Cheng, P.: Improvement in the Mass Resolution of Single Particle Mass Spectrometry Using Delayed Ion Extraction, J. Am. Soc. Mass Spectrom., 29, 2105-2109, https://doi.org/10.1007/s13361-018-2037-4, 2018.

Li, W., Xu, L., Liu, X., Zhang, J., Lin, Y., Yao, X., Gao, H., Zhang, D., Chen, J., Wang, W., Harrison, R. M., Zhang, X., Shao, L., Fu, P., Nenes, A., and Shi, Z.: Air pollution-aerosol interactions produce more bioavailable iron for ocean ecosystems, Sci. Adv., 3, e1601749, https://doi.org/10.1126/sciadv.1601749, 2017.

Mahowald, N. M., Hamilton, D. S., Mackey, K. R. M., Moore, J. K., Baker, A. R., Scanza, R. A., and Zhang, Y.: Aerosol trace metal leaching and impacts on marine microorganisms, Nat. Commun., 9, 2614, https://doi.org/10.1038/s41467-018-04970-7, 2018.

McLean, C. J., Marsh, J. H., Land, A. P., Clark, A., Jennings, R., Ledingham, K. W. D., McCombes, P. T., Marshall, A., Singhal, R. P., and Towrie, M.: Resonant laser ablation (RLA), Int. J. Mass Spectrom., 96, R1-R7, https://doi.org/10.1016/01681176(90)80047-7, 1990.

Moffet, R. C., Furutani, H., Rödel, T. C., Henn, T. R., Sprau, P. O., Laskin, A., Uematsu, M., and Gilles, M. K.: Iron speciation and mixing in single aerosol particles from the Asian continental outflow, J. Geophys. Res., 117, D07204, https://doi.org/10.1029/2011JD016746, 2012.

Morrical, B. D., Fergenson, D. P., and Prather, K. A.: Coupling two-step laser desorption/ionization with aerosol timeof-flight mass spectrometry for the analysis of individual organic particles, J. Am. Soc. Mass Spectrom., 9, 1068-1073, https://doi.org/10.1016/S1044-0305(98)00074-9, 1998.

Murphy, D. M.: The design of single particle laser mass spectrometers, Mass Spectrom. Rev., 26, 150-165, https://doi.org/10.1002/mas.20113, 2007.

Murphy, D. M., Froyd, K. D., Bian, H., Brock, C. A., Dibb, J. E., DiGangi, J. P., Diskin, G., Dollner, M., Kupc, A., Scheuer, E. M., Schill, G. P., Weinzierl, B., Williamson, C. J., and Yu, P.: The distribution of sea-salt aerosol in the global troposphere, Atmos. Chem. Phys., 19, 4093-4104, https://doi.org/10.5194/acp19-4093-2019, 2019.

Neubauer, K. R., Johnston, M. V., and Wexler, A. S.: Humidity effects on the mass spectra of single aerosol particles, Atmos. Environ., 32, 2521-2529, https://doi.org/10.1016/S13522310(98)00005-3, 1998.

Oakes, M., Ingall, E. D., Lai, B., Shafer, M. M., Hays, M. D., Liu, Z. G., Russell, A. G., and Weber, R. J.: Iron solubility related to particle sulfur content in source emission and 
ambient fine particles, Environ. Sci. Technol., 46, 6637-6644, https://doi.org/10.1021/es300701c, 2012.

Passig, J., Schade, J., Oster, M., Fuchs, M., Ehlert, S., Jäger, C., Sklorz, M., and Zimmermann, R.: Aerosol Mass Spectrometer for Simultaneous Detection of Polyaromatic Hydrocarbons and Inorganic Components from Individual Particles, Anal. Chem., 89, 6341-6345, https://doi.org/10.1021/acs.analchem.7b01207, 2017.

Pöschl, U. and Shiraiwa, M.: Multiphase chemistry at the atmosphere-biosphere interface influencing climate and public health in the anthropocene, Chem. Rev., 115, 4440-4475, https://doi.org/10.1021/cr500487s, 2015.

Pratt, K. A. and Prather, K. A.: Mass spectrometry of atmospheric aerosols - recent developments and applications. Part II: On-line mass spectrometry techniques, Mass Spectrom. Rev., 31, 17-48, https://doi.org/10.1002/mas.20330, 2012.

Pratt, K. A., Mayer, J. E., Holecek, J. C., Moffet, R. C., Sanchez, R. O., Rebotier, T. P., Furutani, H., Gonin, M., Fuhrer, K., Su, Y., Guazzotti, S., and Prather, K. A.: Development and characterization of an aircraft aerosol time-of-flight mass spectrometer, Anal. Chem., 81, 1792-1800, https://doi.org/10.1021/ac801942r, 2009

Qin, X., Bhave, P. V., and Prather, K. A.: Comparison of two methods for obtaining quantitative mass concentrations from aerosol time-of-flight mass spectrometry measurements, Anal. Chem., 78, 6169-6178, https://doi.org/10.1021/ac060395q, 2006.

Reilly, P. T. A., Lazar, A. C., Gieray, R. A., Whitten, W. B., and Ramsey, J. M.: The Elucidation of ChargeTransfer-Induced Matrix Effects in Environmental Aerosols Via Real-Time Aerosol Mass Spectral Analysis of Individual Airborne Particles, Aerosol Sci. Technol., 33, 135-152, https://doi.org/10.1080/027868200410895, 2000.

Reinard, M. S. and Johnston, M. V.: Ion formation mechanism in laser desorption ionization of individual nanoparticles, J. Am. Soc. Mass Spectrom., 19, 389-399, https://doi.org/10.1016/j.jasms.2007.11.017, 2008.

Rolph, G., Stein, A., and Stunder, B.: Real-time Environmental Applications and Display sYstem: READY, Environ. Model. Softw., 95, 210-228, https://doi.org/10.1016/j.envsoft.2017.06.025, 2017.

Schade, J., Passig, J., Irsig, R., Ehlert, S., Sklorz, M., Adam, T., Li, C., Rudich, Y., and Zimmermann, R.: Spatially Shaped Laser Pulses for the Simultaneous Detection of Polycyclic Aromatic Hydrocarbons as well as Positive and Negative Inorganic Ions in Single Particle Mass Spectrometry, Anal. Chem., 91, 1028210288, https://doi.org/10.1021/acs.analchem.9b02477, 2019.

Schoolcraft, T. A., Constable, G. S., Zhigilei, L. V., and Garrison, B. J.: Molecular dynamics simulation of the laser disintegration of aerosol particles, Anal. Chem., 72, 5143-5150, https://doi.org/10.1021/ac0007635, 2000.

Seder, T. A., Ouderkirk, A. J., and Weitz, E.: The wavelength dependence of excimer laser photolysis of $\mathrm{Fe}(\mathrm{CO}) 5$ in the gas phase. Transient infrared spectroscopy and kinetics of the $\mathrm{Fe}(\mathrm{CO}) x$ $(x=4,3,2)$ photofragments, J. Chem. Phys., 85, 1977-1986, https://doi.org/10.1063/1.451141, 1986.

Seinfeld, J. H. and Pandis, S. N.: Atmospheric chemistry and physics: From air pollution to climate change, 3rd edn., Wiley, Hoboken, New Jersey, 1120 pp., 2016.
Shen, X., Saathoff, H., Huang, W., Mohr, C., Ramisetty, R., and Leisner, T.: Understanding atmospheric aerosol particles with improved particle identification and quantification by singleparticle mass spectrometry, Atmos. Meas. Tech., 12, 2219-2240, https://doi.org/10.5194/amt-12-2219-2019, 2019.

Silva, P. J. and Prather, K. A.: Interpretation of Mass Spectra from Organic Compounds in Aerosol Time-ofFlight Mass Spectrometry, Anal. Chem., 72, 3553-3562, https://doi.org/10.1021/ac9910132, 2000.

Sofiev, M., Winebrake, J. J., Johansson, L., Carr, E. W., Prank, M., Soares, J., Vira, J., Kouznetsov, R., Jalkanen, J.-P., and Corbett, J. J.: Cleaner fuels for ships provide public health benefits with climate tradeoffs, Nat. Commun., 9, 406, https://doi.org/10.1038/s41467-017-02774-9, 2018.

Song, X.-H., Hopke, P. K., Fergenson, D. P., and Prather, K. A.: Classification of Single Particles Analyzed by ATOFMS Using an Artificial Neural Network, ART-2A, Anal. Chem., 71, 860865, https://doi.org/10.1021/ac9809682, 1999.

Stein, A. F., Draxler, R. R., Rolph, G. D., Stunder, B. J. B., Cohen, M. D., and Ngan, F.: NOAA's HYSPLIT atmospheric transport and dispersion modeling system, B. Am. Meteorol. Soc., 96, 2059-2077, https://doi.org/10.1175/BAMS-D-14-00110.1, 2015.

Su, Y., Sipin, M. F., Furutani, H., and Prather, K. A.: Development and characterization of an aerosol time-of-flight mass spectrometer with increased detection efficiency, Anal. Chem., 76, 712719, https://doi.org/10.1021/ac034797z, 2004.

Sullivan, R. C., Guazzotti, S. A., Sodeman, D. A., and Prather, K. A.: Direct observations of the atmospheric processing of Asian mineral dust, Atmos. Chem. Phys., 7, 1213-1236, https://doi.org/10.5194/acp-7-1213-2007, 2007.

Sultana, C. M., Cornwell, G. C., Rodriguez, P., and Prather, K. A.: FATES: a flexible analysis toolkit for the exploration of singleparticle mass spectrometer data, Atmos. Meas. Tech., 10, 1323 1334, https://doi.org/10.5194/amt-10-1323-2017, 2017.

Thomson, D. S., Middlebrook, A. M., and Murphy, D. M.: Thresholds for Laser-Induced Ion Formation from Aerosols in a Vacuum Using Ultraviolet and Vacuum-Ultraviolet Laser Wavelengths, Aerosol Sci. Technol., 26, 544-559, https://doi.org/10.1080/02786829708965452, 1997.

Toner, S. M., Sodeman, D. A., and Prather, K. A.: Single Particle Characterization of Ultrafine and Accumulation Mode Particles from Heavy Duty Diesel Vehicles Using Aerosol Timeof-Flight Mass Spectrometry, Environ. Sci. Technol., 40, 39123921, https://doi.org/10.1021/es051455x, 2006.

Trainor, D. W. and Mani, S. A.: Pumping iron: A KrF laser pumped atomic iron laser, J. Chem. Phys., 68, 5481-5485, https://doi.org/10.1063/1.435727, 1978.

Uski, O., Jalava, P. I., Happo, M. S., Torvela, T., Leskinen, J., Mäki-Paakkanen, J., Tissari, J., Sippula, O., Lamberg, H., Jokiniemi, J., and Hirvonen, M.-R.: Effect of fuel zinc content on toxicological responses of particulate matter from pellet combustion in vitro, Sci. Total Environ., 511, 331-340, https://doi.org/10.1016/j.scitotenv.2014.12.061, 2015.

Vera, C. C., Trimborn, A., Hinz, K.-P., and Spengler, B.: Initial velocity distributions of ions generated by in-flight laser desorption/ionization of individual polystyrene latex microparticles as studied by the delayed ion extraction method, Rapid Commun. Mass Spectrom., 19, 133-146, https://doi.org/10.1002/rcm.1753, 2005 . 
Verdun, F. R., Krier, G., and Muller, J. F.: Increased sensitivity in laser microprobe mass analysis by using resonant two-photon ionization processes, Anal. Chem., 59, 1383-1387, https://doi.org/10.1021/ac00137a003, 1987.

Wade, E. E., Farquar, G. R., Steele, P. T., McJimpsey, E. L., Lebrilla, C. B., and Fergenson, D. P.: Wavelength and size dependence in single particle laser aerosol mass spectra, J. Aerosol Sci., 39, 657-666, https://doi.org/10.1016/j.jaerosci.2008.03.007, 2008.

Wang, G., Zhang, R., Gomez, M. E., Yang, L., Levy Zamora, M., Hu, M., Lin, Y., Peng, J., Guo, S., Meng, J., Li, J., Cheng, C., Hu, T., Ren, Y., Wang, Y., Gao, J., Cao, J., An, Z., Zhou, W., Li, G., Wang, J., Tian, P., Marrero-Ortiz, W., Secrest, J., Du, Z., Zheng, J., Shang, D., Zeng, L., Shao, M., Wang, W., Huang, Y., Wang, Y., Zhu, Y., Li, Y., Hu, J., Pan, B., Cai, L., Cheng, Y., Ji, Y., Zhang, F., Rosenfeld, D., Liss, P. S., Duce, R. A., Kolb, C. E., and Molina, M. J.: Persistent sulfate formation from London Fog to Chinese haze, P. Natl. Acad. Sci. USA, 113, 13630-13635, https://doi.org/10.1073/pnas.1616540113, 2016.

Woods, E., Smith, G. D., Dessiaterik, Y., Baer, T., and Miller, R. E.: Quantitative Detection of Aromatic Compounds in Single Aerosol Particle Mass Spectrometry, Anal. Chem., 73, 23172322, https://doi.org/10.1021/ac0011661, 2001.

Ye, D., Klein, M., Mulholland, J. A., Russell, A. G., Weber, R., Edgerton, E. S., Chang, H. H., Sarnat, J. A., Tolbert, P. E., and Ebelt Sarnat, S.: Estimating Acute Cardiovascular Effects of Ambient $\mathrm{PM}_{2.5}$ Metals, Environ. Health Persp., 126, 27007, https://doi.org/10.1289/EHP2182, 2018.
Young, J. P., Shaw, R. W., and Smith, D. H.: Resonance ionization mass spectrometry, Anal. Chem., 61, 1271A-1279A, https://doi.org/10.1021/ac00197a002, 1989.

Zhang, G., Bi, X., Lou, S., Li, L., Wang, H., Wang, X., Zhou, Z., Sheng, G., Fu, J., and Chen, C.: Source and mixing state of iron-containing particles in Shanghai by individual particle analysis, Chemosphere, 95, 9-16, https://doi.org/10.1016/j.chemosphere.2013.04.046, 2014.

Zhou, Y., Huang, X. H., Griffith, S. M., Li, M., Li, L., Zhou, Z., Wu, C., Meng, J., Chan, C. K., Louie, P. K. K., and Yu, J. Z.: A field measurement based scaling approach for quantification of major ions, organic carbon, and elemental carbon using a single particle aerosol mass spectrometer, Atmos. Environ., 143, 300312, https://doi.org/10.1016/j.atmosenv.2016.08.054, 2016.

Zimmermann, R., Ferge, T., Gälli, M., and Karlsson, R.: Application of single-particle laser desorption/ionization time-of-flight mass spectrometry for detection of polycyclic aromatic hydrocarbons from soot particles originating from an industrial combustion process, Rapid Commun. Mass Spectrom., 17, 851-859, https://doi.org/10.1002/rcm.979, 2003. 